\title{
Short-Term (-)-Hydroxycitrate Ingestion Increases Fat Oxidation during Exercise in Athletes
}

\author{
Kiwon Lim ${ }^{1, *}$, Sungpil Ryu ${ }^{1}$, Yasuyuki OHISHI ${ }^{2}$, Itaru WATANABE ${ }^{2}$, Hironori TomI ${ }^{3}$, \\ Heajung $\mathrm{SuH}^{1}$, Woong-Ki LEE ${ }^{4}$ and Taedong KWON ${ }^{5}$ \\ ${ }^{1}$ Institute of Elderly Health, 1F, \#948-27 Dokok-dong, Kangnam-gu, Seoul, Korea \\ ${ }^{2}$ Nippon Meat Packers, Shizuoka, Japan \\ ${ }^{3}$ Nipponshinyaku Co., Kyoto, Japan \\ ${ }^{4}$ Konkuk University, Seoul 143-701, Korea \\ ${ }^{5}$ Taegu University, Taegu, Korea \\ (Received October 13, 2001)
}

\begin{abstract}
Summary (-)-Hydroxycitrate (HCA) is known to inhibit increasing malonyl CoA concentration during endurance exercise. Furthermore, a short-term administration of HCA enhances endurance exercise performance in mice. Therefore we investigated the shortterm administration of HCA on the exercise performance of athletes. Subjects were administered $250 \mathrm{mg}$ of HCA or placebo as a control $(\mathrm{CON})$ for $5 \mathrm{~d}$, after each time performing cycle ergometer exercise at $60 \% \mathrm{VO}_{2} \max$ for 60 min followed by $80 \% \mathrm{VO}_{2} \max$ until exhaustion. Blood was collected and expired gas samples analyzed at rest and every $15 \mathrm{~min}$. The respiratory exchange ratio was significantly lower in the HCA trial than in the CON trial $(p<0.05)$. Fat oxidation was significantly increased by short-term administration of HCA, and carbohydrate oxidation was significantly decreased $(p<0.05)$ during exercise, presumably resulting in increasing the cycle ergometer exercise time to exhaustion after $1 \mathrm{~h}$ of $60 \% \mathrm{VO}_{2}$ max exercise $(p<0.05)$. These results suggest that a short-term administration of HCA enhances endurance performance with increasing fat oxidation, which spares glycogen utilization during moderate intensity exercise in athletes.
\end{abstract}

Key Words (-)-hydroxycitrate (HCA), endurance performance, respiratory exchange ratio, carbohydrate oxidation

Many dietary supplements are used to increase exercise performance on the athletic field (1). Coaches and athletes expect that these supplements might compensate for a lack of training (2). Actually, several studies revealed that of most importance might be the sparing effect of glycogen utilization during exercise through an increase in the ability of skeletal muscle to oxidize lipids $(3,4)$.

There has been much researches and unpublished observations over the past decades demonstrating the importance of muscle and liver glycogen in reducing fatigue and improving athletic performance. This is because when muscle glycogen and blood glucose concentrations are low, the intensity of exercise must be reduced to a level that can be supported by the body's limited ability to convert body fat into energy (5). Focusing on these suggestions, many researchers $(6-8)$ have reported that caffeine has a positive ergogenic effect. They proposed that it is achieved by an elevation in catecholamines, which enhance fat oxidation either by increasing free fatty acid (FFA) levels or by intramuscular triacylglycerol lipolysis (6). Blood FFA was elevated $1 \mathrm{~h}$ after caffeine ingestion in some studies (9-11). We have suggested that many kinds of supplements such as caf-

* To whom correspondence should be addressed.

E-mail: kwlim21@hotmail.com feine $(8,10)$, capsaicin $(12,13)$, red pepper $(14,15)$, and carnitine (16) affected the endurance performance in animals and athletes.

Recently, (-)-hydroxycitrate (HCA) has become known to reduce body fat accumulation after a few weeks of ingestion (17). HCA, a potent inhibitor of ATP citrate-lyase (EC 4.1.3.8, 18), inhibits fatty acid synthesis and reduces appetite in rodents (19). It inhibits citrate conversion into acetyl $\mathrm{CoA}$ in cells as a result of acetyl CoA convert into malonyl CoA; therefore fat oxidation may increase in skeletal muscle during endurance exercise performance (2). Malonyl CoA is an inhibitor of carnitine palmitoyltransferase I, the enzyme that controls the oxidation of fatty acids by regulating their transfer into the mitochondria. We hypothesized that during prolonged endurance exercise, carbohydrate oxidation was increased by acetyl CoA conversion into malonyl CoA, which caused fatigue in athletes. We reported that a short-term administration of HCA promotes fat oxidation and spares carbohydrate utilization in mice at rest and during exercise (2). However, there is little evidence of its effectiveness in humans.

In this paper we present evidence on whether shortterm ingestion of HCA increases fat oxidation that results in carbohydrate sparing and enhances endurance exercise performance in athletes. 


\section{METHODS}

Subjects. Six elite male athletes agreed to participate in the study after being informed of the nature of the experiments. The subjects were nonsmokers and had been training $6 \mathrm{~d}$ a week and participating in competitive matches several times a year. They have been training at least $6 \mathrm{~h} / \mathrm{d}$ for $5 \mathrm{~d} / \mathrm{wk}$. They were living in a dormitory and had the same diet contents 3,500 $\mathrm{kcal} / \mathrm{d}$. Their characteristics: $19.33 \pm 0.82 \mathrm{y}$ old, $177.80 \pm 3.70 \mathrm{~cm}$ tall, $72.88 \pm 3.85 \mathrm{~kg}$ weight, and $10.63 \pm 0.91 \%$ of body fat (Table 1). Each subject signed a consent form that outlined possible risks of the procedure. The protocol was approved by Institute of Natural Sciences of Taegu University in accordance with the Helsinki Declaration of 1975.

Experimental procedure. Subjects reported to the laboratory before the start of the experiment for an incremental maximum oxygen consumption $\left(\mathrm{VO}_{2} \max \right)$ test on a cycle ergometer as reported by Lim et al. (14). Their mean $\mathrm{VO}_{2} \max$ was $59.91 \pm 3.85 \mathrm{~mL} \cdot \mathrm{kg}^{-1} \cdot \mathrm{min}^{-1}$. We calculated their exact $60 \%$ and $80 \%$ of $\mathrm{VO}_{2}$ max exercise bout based on their $\mathrm{VO}_{2}$ max.

The subjects were requested to maintain similar training patterns throughout the duration of the experiments. Moreover, they were requested to consume the same diets from the first day of the experiment to the end, except for HCA (Soluble type; Nippon-Shinyaku Co., Japan). Two tablets, each containing $125 \mathrm{mg}$ of HCA, had to be taken just after breakfast or lunch $5 \mathrm{~d} /$ wk. The same amount of a flour tablet was used as control (CON) for $5 \mathrm{~d} / \mathrm{wk}$. During the experimental periods, the subjects were educated to avoid sources of methylxanthines such as tea, coffee, chocolate, cola, and caffeine-containing over-the-counter pharmaceuticals. The HCA or placebo was ingested for $5 \mathrm{~d}$ in a double-blind manner. At least $2 \mathrm{~d}$ between trials were established to minimize any possible effects of the HCA.

Table 1. Physical characteristics of the subjects.

$\begin{array}{lr}\text { Age }(\mathrm{y}) & 19.3 \pm 0.8 \\ \text { Height }(\mathrm{cm}) & 177.8 \pm 3.7 \\ \text { Body weight }(\mathrm{kg}) & 72.9 \pm 3.9 \\ \text { Body fat }(\%)^{*} & 10.6 \pm 0.9 \\ \mathrm{VO}_{2} \mathrm{max}(\mathrm{mL} / \mathrm{kg} / \mathrm{min}) & 59.9 \pm 3.9\end{array}$

Values are mean \pm SE. * Body fat was analyzed by a body fat analyzer (TBF-105, Tanita, Japan).
Experimental design. The protocol for each trial was designed in the same method. Subjects reported to the laboratory $2 \mathrm{~h}$ before the start of the experiment (09: 00). They ingested a 640-kcal meal (bread, eggs, orange juice) and the HCA or CON $2 \mathrm{~h}$ before the exercise as reported previously (8). After the meal, the subjects were allowed to rest in a seated position. After resting for $100 \mathrm{~min}$, they warmed up with $10 \mathrm{~min}$ of stretching exercises 20 min before exercise. During the resting periods, a venous 3-way catheter was inserted into the antecubital vein and was kept patent with a saline infusion. A resting blood sample and expired gas were collected and analyzed.

The subjects exercised by the use of a bicycle ergometer (Recoher, LODE Medical, Netherlands) at a pedaling frequency of $50 \mathrm{rpm}$ and an intensity of $60 \%$ of $\mathrm{VO}_{2}$ max for $60 \mathrm{~min}$; the intensity was then elevated to $80 \%$ until exhaustion. The two-intensity exercise $(60 \%$ for $60 \mathrm{~min}$ and $80 \% \mathrm{VO}_{2}$ max exercise until exhaustion) protocol is to investigate endurance performance $(8$, 10).

Samples for expired air were analyzed every $5 \mathrm{~min}$ for $60 \mathrm{~min}$ at $60 \%$ of their $\mathrm{VO}_{2} \max$ and for $5 \mathrm{~min}$ at $80 \%$ $\mathrm{VO}_{2}$ max. Blood samples $(5 \mathrm{~mL})$ were taken every $15 \mathrm{~min}$ for $60 \mathrm{~min}$ of the exercise at $60 \% \mathrm{VO}_{2} \max$ and $5 \mathrm{~min}$ of $80 \% \mathrm{VO}_{2}$ max. The investigator determined exercise time to exhaustion when the revolution could no longer be maintained three times at $50 \mathrm{rpm}$ of pedaling. The rate of perceived exertion (RPE) was requested every $5 \mathrm{~min}$ for $65 \mathrm{~min}$ of the exercise bout. The subjects had no indication of time after the 65 min sampling period until exhaustion. The procedures of the experiment were performed in a laboratory chamber with a room temperature of $20^{\circ} \mathrm{C}$ and humidity of $50 \%$. The experimental design is shown in Fig. 1.

Analysis. Expired gas samples were analyzed on an $\mathrm{O}_{2} / \mathrm{CO}_{2}$ Auto-analyzer (QUARK PFT, COSMED, Italy) previously calibrated for $\mathrm{O}_{2}$ and $\mathrm{CO}_{2}$. Fat and carbohydrate oxidation during exercise was calculated as previously described (2). The oxygen consumption $\left(\mathrm{VO}_{2}\right)$, carbon dioxide exhaustion $\left(\mathrm{VCO}_{2}\right)$, RER, carbohydrate oxidation, and fat oxidation was calculated as follows:

$$
\begin{aligned}
& \mathrm{VO}_{2}=\left[\left(\mathrm{FEN}_{2} / \mathrm{FIN}_{2}\right) * \mathrm{FIO}_{2}-\mathrm{FEO}_{2}\right] * \mathrm{Ve}, \\
& \mathrm{VCO}_{2}=\left(\mathrm{FECO}_{2}-\mathrm{FICO}_{2}\right) * \mathrm{Ve}, \\
& \mathrm{RER}=\mathrm{VCO}_{2} / \mathrm{VO}_{2}, \\
& \text { Carbohydrate oxidation } \\
& \quad=(4.51 * \mathrm{RER}-3.18) * \mathrm{VO}_{2},
\end{aligned}
$$

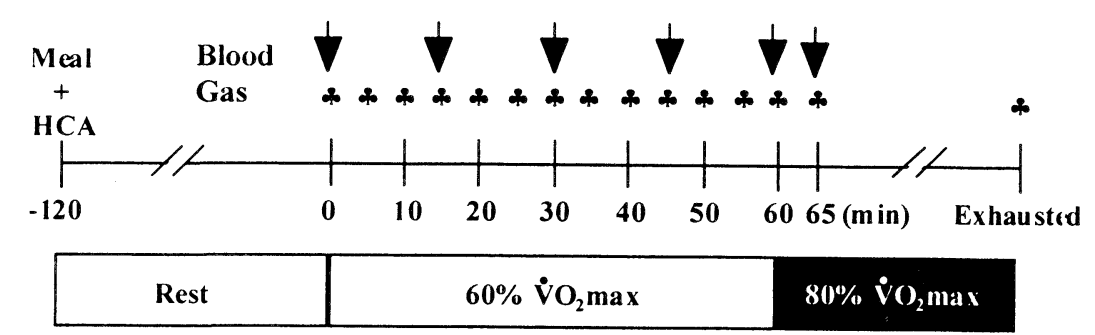

Fig. 1. Experimental design. 
Fat oxidation $=1.67 *(1-\mathrm{RER}) * \mathrm{VO}_{2}$,

FEN $_{2}$, concentration of nitrogen in the exhaust air; $\mathrm{FIN}_{2}$, concentration of nitrogen in the room air; $\mathrm{FEO}_{2}$, concentration of oxygen in the exhaust air; $\mathrm{FIO}_{2}$, concentration of oxygen in the room air; $\mathrm{FECO}_{2}$, concentration of carbon dioxide in the exhaust air; $\mathrm{FICO}_{2}$, concentration of carbon dioxide in the room air; Ve, ventilation corrected to standard temperature and pressure.

Blood samples were collected with a heparinized tube. Whole blood $500 \mu \mathrm{L}$ was immediately separated into a microcentrifuge tube for blood glucose and lactate analyses by the use of an autoanalysis system (YSI 2300 Plus, Yellow Springs Institute, USA). Another blood sample was centrifuged, and plasma was collected and stored in $\mathrm{a}-70^{\circ} \mathrm{C}$ freezer for future analysis.

Plasma FFA (NEFAzyme-Kit, Eiken, Tokyo, Japan) and glycerol (Boehringer Mannheim, Gmbh., Germany) concentrations were determined by enzymatically using a kit as previously described by Lim et al. (14).

Statistical analysis. The results are described as mean \pm SE. The data were analyzed with a two-way

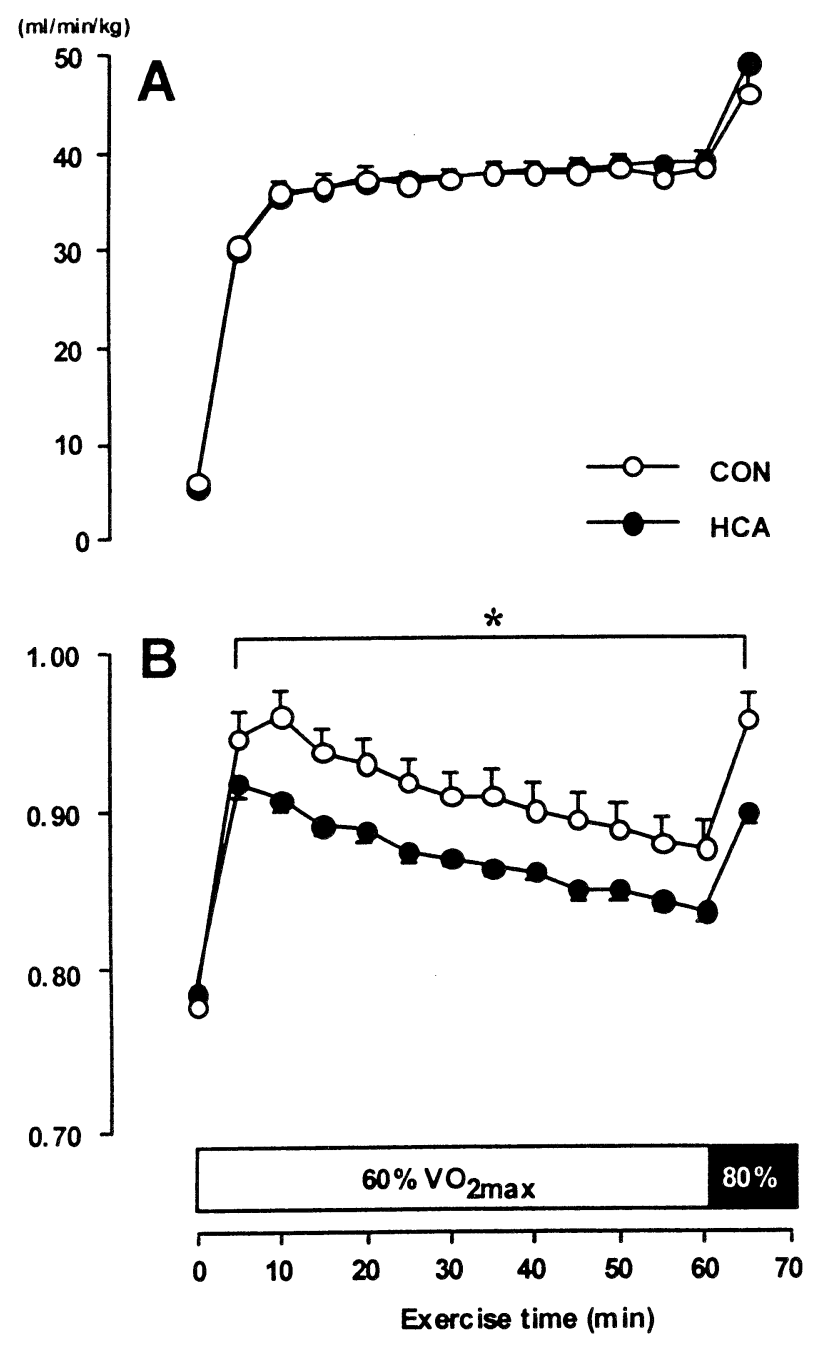

Fig. 2. Oxygen consumption (A) and respiratory exchange ratio (B) during exercise after $5 \mathrm{~d}$ of HCA ingestion. Values are means \pm SE. Open circle $(O)$ : control; closed circle $(\mathbf{)})$ : HCA. ${ }^{*}$ Statistically significant from the values of the control trial $(p<0.05)$.
ANOVA repeated measure. Exercise time (12 time points) and supplementation type (Placebo and HCA) were the independent variables. Significant differences between means were determined with a Newman Kuels post hoc test. The level of significance was set at $p<0.05$.

\section{RESULTS}

Oxygen consumption

The ingestion of the $250 \mathrm{mg} \mathrm{HCA}$ for $5 \mathrm{~d}$ did not affect $\mathrm{VO}_{2}$ at rest or during the $60 \% \mathrm{VO}_{2}$ max ergometer exercise for $60 \mathrm{~min}$ (Fig. 2A). However, it produced a slight increase in $\mathrm{VO}_{2}$ at $60 \mathrm{~min}$ and $65 \mathrm{~min}$ of $80 \%$ $\mathrm{VO}_{2}$ max, but it was not significant.

Respiratory exchange ratio (RER)

The RER was significantly lower in the HCA trial than in the CON trial throughout the exercise (Fig. 2B). Substrate oxidation

The carbohydrate oxidation decreased significantly in the HCA trial from $10 \mathrm{~min}$ to $65 \mathrm{~min}$ of the exercise (Fig. 3A). And the fat oxidation significantly increased in the HCA trial at the same period (Fig. 3B).

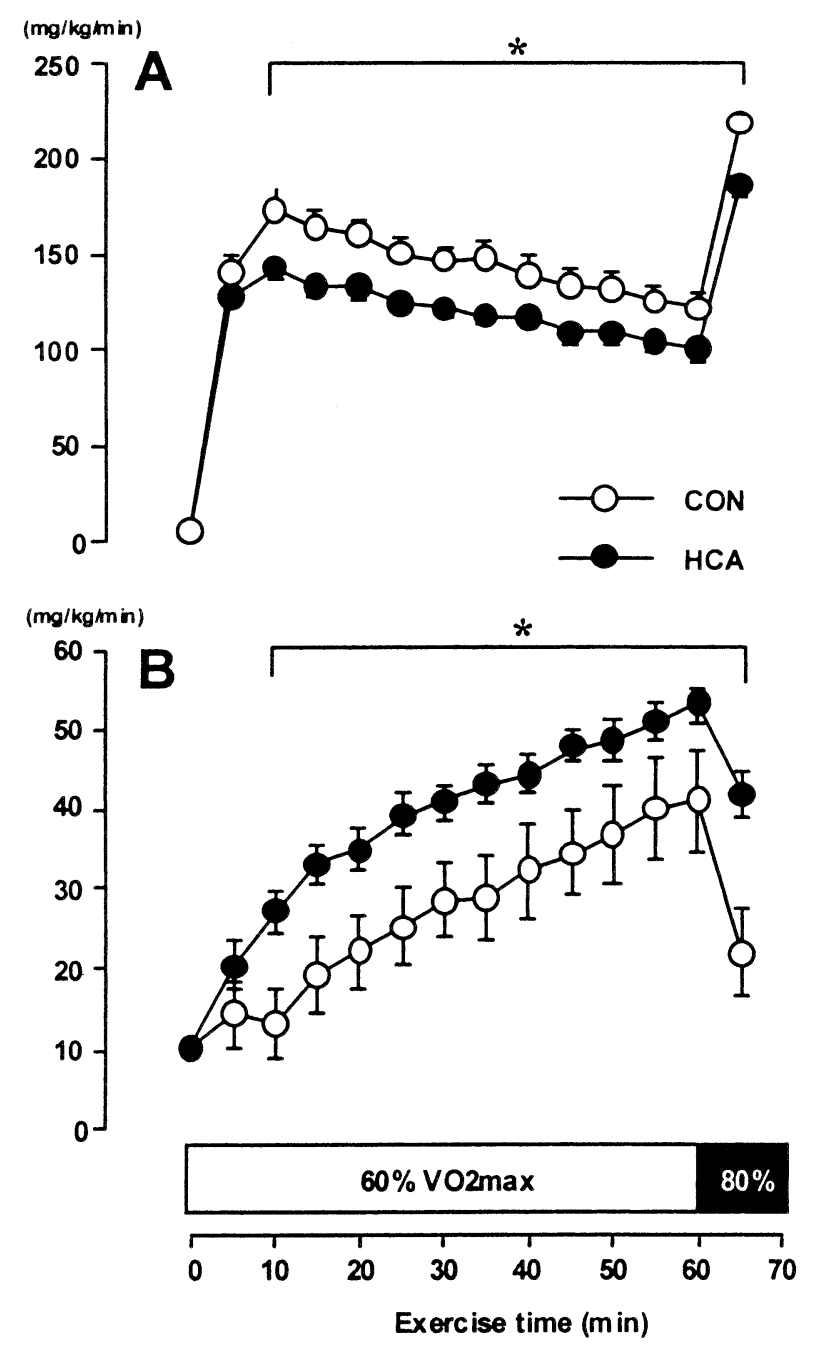

Fig. 3. Carbohydrate oxidation (A) and fat oxidation (B) during the exercise after $5 \mathrm{~d}$ of HCA ingestion. Values are means \pm SE. Open circle $(O)$ : control; closed circle (O): HCA. * Statistically significant from the values of the control trial $(p<0.05)$. 
Table 2. Changes of blood substrates during moderate- to high-intensity cycle ergometer exercise with and without HCA.

\begin{tabular}{|c|c|c|c|c|c|c|c|}
\hline & & \multicolumn{6}{|c|}{ Exercise time (min) } \\
\hline & & 0 & 15 & 30 & 45 & 60 & 65 \\
\hline \multirow{3}{*}{$\begin{array}{l}\text { Glucose } \\
\qquad(\mathrm{mmol} / \mathrm{L})\end{array}$} & $\mathrm{CON}$ & 4.19 & 3.85 & 4.15 & 3.90 & 3.82 & 4.30 \\
\hline & & 0.19 & 0.30 & 0.08 & 0.34 & 0.10 & 0.09 \\
\hline & $\mathrm{HCA}$ & 3.85 & 3.86 & 4.17 & $4.28^{*}$ & * 4.10 & 4.14 \\
\hline \multirow{5}{*}{$\begin{array}{l}\text { Lactate } \\
\qquad(\mathrm{mmol} / \mathrm{L})\end{array}$} & & 0.23 & 0.12 & 0.13 & 0.08 & 0.09 & 0.68 \\
\hline & $\mathrm{CON}$ & 0.97 & 2.34 & 2.08 & 1.70 & 1.51 & 4.63 \\
\hline & & 0.03 & 0.23 & 0.26 & 0.30 & 0.24 & 0.14 \\
\hline & HCA & 1.05 & 2.32 & 1.92 & 1.59 & 1.33 & $3.90^{*}$ \\
\hline & & 0.08 & 0.11 & 0.14 & 0.16 & 0.14 & 0.17 \\
\hline \multirow{4}{*}{$\begin{array}{l}\text { FFA } \\
\qquad(\mathrm{mmol} / \mathrm{L})\end{array}$} & $\mathrm{CON}$ & 0.27 & 0.21 & 0.38 & 0.43 & 0.47 & 0.22 \\
\hline & & 0.02 & 0.01 & 0.03 & 0.02 & 0.03 & 0.02 \\
\hline & $\mathrm{HCA}$ & 0.30 & 0.18 & 0.40 & 0.42 & 0.54 & $0.31^{*}$ \\
\hline & & 0.02 & 0.01 & 0.02 & 0.03 & 0.03 & 0.02 \\
\hline \multirow{4}{*}{$\begin{array}{l}\text { Glycerol } \\
\qquad(\mathrm{mmol} / \mathrm{L})\end{array}$} & $\mathrm{CON}$ & 0.26 & 0.39 & 0.40 & 0.52 & 0.72 & 0.65 \\
\hline & & 0.02 & 0.02 & 0.02 & 0.04 & 0.04 & 0.09 \\
\hline & $\mathrm{HCA}$ & 0.25 & 0.35 & 0.47 & 0.61 & 0.81 & 0.64 \\
\hline & & 0.02 & 0.02 & 0.05 & 0.03 & 0.06 & 0.06 \\
\hline
\end{tabular}

Values are mean and SE.

* Statistically significant from control at $p<0.05$, respectively.

\section{Blood measurements}

The blood glucose concentration was not significantly different at rest or during exercise between the trials, excepting $45 \mathrm{~min}$ of exercise (Table 2).

The blood lactate level was not significantly changed by $\mathrm{HCA}$ ingestion during $60 \% \mathrm{VO}_{2}$ max exercise, but it was lower in the HCA trial when the exercise intensity increased to $80 \% \mathrm{VO}_{2} \max$ at $65 \mathrm{~min}$ of the exercise (Table 2).

Plasma FFA levels were not higher in the HCA trial during the $60 \% \mathrm{VO}_{2}$ max exercise, though fat oxidation was higher in the HCA trial. However, it was significantly higher in the HCA trial than in the CON trial when exercise intensity was increased to $80 \% \mathrm{VO}_{2} \max$ at $65 \mathrm{~min}$ of the exercise.

Plasma glycerol concentration during the exercise was not significantly affected by the HCA ingestion (Table 2).

Ratings of perceived exertion (RPE)

RPE was significantly lower in the HCA trial from $15 \mathrm{~min}$ of the $60 \% \mathrm{VO}_{2} \max$ exercise to exhaustion (Fig. 4). Moreover, it was significantly lower in the HCA trial than in the CON trial when the exercise intensity increased to $80 \% \mathrm{VO}_{2} \max (p<0.05)$.

Endurance capacity

Exercise time to exhaustion at $80 \% \mathrm{VO}_{2} \max$ after $60 \% \mathrm{VO}_{2}$ max for 60 min was significantly longer in the HCA trial than in the CON trial (Fig. 5).

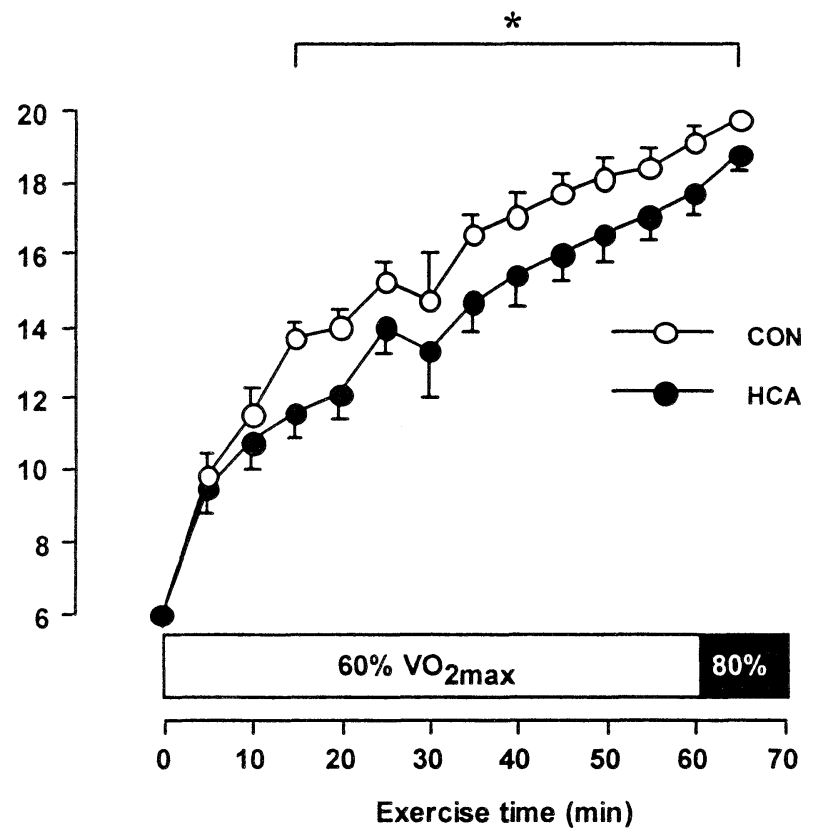

Fig. 4. Ratings of perceived exertion (RPE) during the exercise after $5 \mathrm{~d}$ of HCA ingestion. Values are means \pm SE. Open circle $(\bigcirc)$ : control; closed circle $(\bullet)$ : HCA. * Statistically significant from the values of the control trial $(p<0.05)$.

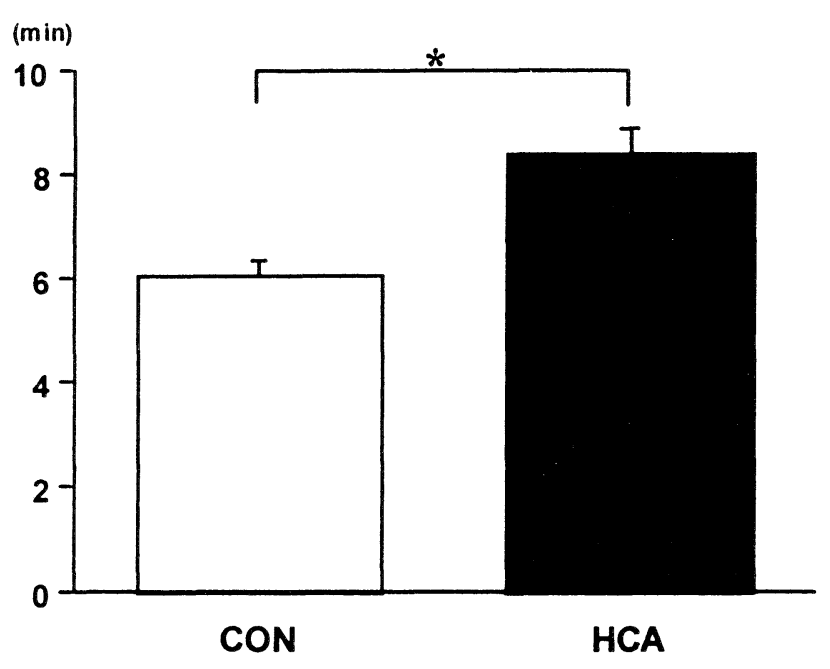

Fig. 5. Exercise time to exhaustion at $80 \% \mathrm{VO}_{2} \max$ after $60 \% \mathrm{VO}_{2} \max$ for $60 \mathrm{~min}$ during the exercise after $5 \mathrm{~d}$ of HCA ingestion. Values are means \pm SE. Open bar $(\square)$ : control; closed bar $(\mathbf{\square})$ : HCA. * Statistically significant from the values of the control trial $(p<0.05)$.

\section{DISCUSSION}

The aim of the present study was to investigate the effects of the HCA short-term ingestion on endurance exercise performance in athletes. We show in this study that an ingestion of $250 \mathrm{mg}$ HCA for $5 \mathrm{~d}$ increases fat oxidation and decreases the ratings of perceived exertion resulting in an improvement of endurance performance.

Interests in this kind of study are aroused by the possibility of enhancing endurance exercise, by using ergogenic supplements, such as sports beverages, caf- 
feine, capsaicin, and carnitine, that maintain blood glucose concentration or increase fat mobilization and/or fat oxidation. Of these, HCA is known to enhance endurance exercise performance in mice (2).

Watson and Lowenstein (19) first identified HCA as a potent competitive inhibitor of the extramitochondrial enzyme ATP-lyase. They subsequently demonstrated both in vitro and in vivo that HCA in animals not only inhibited the actions of citrate cleavage enzyme and suppressed de novo fatty acid synthesis (20), but also increased the rates of hepatic glycogen synthesis and decreased body weight gain (18). HCA-related research combined with exercise was only in mice (2) and humans (22).

Van Loon et al. (22) have reported that an acute ingestion of HCA did not support the hypothesis that HCA alters the short-term rate of fat oxidation in the fasting state during rest or moderate exercise. However, they used the insoluble HCA, calcium-attached formula in the study. Soluble HCA is possibly extracted with sodium salt. Therefore calcium-attached HCA was less soluble and less absorbed in the intestine than the sodium salt. On the other hand, Ishihara et al. (2) reported that a short-term ingestion of the soluble HCA enhances fat oxidation and endurance exercise performance in mice.

In the present study, blood glucose and lactate levels during a $60 \% \mathrm{VO}_{2}$ max ergometer exercise were not significantly changed by the HCA ingestion. In an $80 \%$ $\mathrm{VO}_{2}$ max exercise, however, lactate concentration was lower in the HCA trial than in the CON trial (Table 2). Van Loon et al. (22) also reported that the lactate concentration was slightly decreased by acute ingestion of HCA during exercise. These findings suggest that by short-term or acute ingestion of HCA, more fat was utilized as the energy source during moderate-intensity exercise. Therefore we could carefully suggest that HCA ingestion might postpone a lactate threshold (LT), since HCA has an inhibiting effect on carbohydrate oxidation $(2,23)$. In other words, HCA ingestion could enhance endurance performance because it is believed that LT is an important factor for endurance performance without increasing $\mathrm{VO}_{2} \max (24,25)$. However, the detailed effects of HCA ingestion on LT level remain to be clarified.

Ishihara et al. (2) reported that acute ingestion of HCA does not affect RER, even though FFA concentration was increased. Furthermore, they also suggested that an acute ingestion of HCA increased serum FFA concentration $100 \mathrm{~min}$ after the administration and that lipid metabolism may be promoted and carbohydrate utilization could be spared. As we previously reported, increased FFA concentration might have a glycogen sparing effect by caffeine ingestion (8). Caffeine has a strong effect of fat mobilization compared with other supplements, as we previously investigated with capsaicin or carnitine $(12,26)$. However, the HCA mechanism is different from that for caffeine and carnitine. As shown in Table 2, plasma glycerol concentration was not increased by the HCA ingestion, which in- dicates that fat mobilization by short-term HCA ingestion did not occur during endurance exercise performance. In regard to this point of view, our data for the plasma FFA level in this study using athletes were not consistent with the report of Ishihara et al. (2) using mice. However, FFA concentration was significantly higher in the HCA trial than in the CON trial at $80 \%$ $\mathrm{VO}_{2}$ max exercise, suggesting that by short-term HCA ingestion, fatty acids were used more as an energy source than they were reesterified in the adipocytes during moderate intensity exercise.

An acute administration of HCA did not affect energy substrate utilization more $(2,21,22)$. However, chronically administered HCA affects the RER, which was lower during the $60 \mathrm{~min}$ running period, and lipid oxidation was significantly greater and carbohydrate oxidation was significantly less than the control trial (2). In the present study, as shown in Fig. 2B, RER in the HCA trial was significantly lower than in the CON trial, even though similar concentrations of serum FFA and glycerol (Table 2). Furthermore, fat oxidation (Fig. 4B) was significantly higher in the HCA at a similar time point of RER, but carbohydrate oxidation showed a reverse result of fat oxidation (Fig. 4A). It might be suggested that HCA suppressed stored glycogen utilization during moderate-intensity exercise. This spared glycogen might be used effectively at the latter stage of endurance exercise. Actually, our experimental protocol was composed of two different exercise intensities at $60 \% \mathrm{VO}_{2}$ max for $1 \mathrm{~h}$ followed by $80 \% \mathrm{VO}_{2}$ max until exhausted. These two intensities showed the effects of glycogen sparing during prolonged endurance exercise performance. These RER, fat oxidation, and carbohydrate oxidation data at $80 \% \quad \mathrm{VO}_{2} \max$ exercise also showed higher fat oxidation.

The enhancement of fat oxidation at the early stage of exercise could lead to increased endurance exercise capacity. In the present study, the ergometer exercise time to exhaustion was significantly delayed $2.37 \mathrm{~min}$ after $1 \mathrm{~h}$ of $60 \% \mathrm{VO}_{2} \max$ exercise in the HCA trial. The promotion of fat oxidation with a short-term administration of HCA may be attributed to the activity of carnitine palmitoyltransferase I (CPT I), which plays an important role in regulating the flux of long-chain fatty acids into the mitochondrial membrane to oxidation (26). Malonyl CoA inhibits CPT I activity in the cytosol, but its effect was suppressed by HCA, as discussed above.

In summary, the short-term administration of HCA enhanced fatty acid utilization and less accumulation of lactate during exercise at the two different intensities. Moreover, HCA administration significantly reduced the RER and enhanced fat oxidation during moderate-intensity exercise. Increased fat oxidation reduced the carbohydrate oxidation during the first stage of exercise. These results suggest that an enhancement of fat oxidation and endurance-exercise capacity by a short-term administration of HCA in athletes might have glycogensparing effects during moderate-intensity exercise. 


\section{Acknowledgments}

The authors gratefully thank the Soccer Team of Taegu University for its participation as the subjects, and Ki-Hoon Kim and Keun-Soo Lee for their technical assistance with the exercise program.

This paper was partly supported by a Research Grant from Konkuk University in 1999.

\section{REFERENCES}

1) Applegate EA, Grivetti LE. 1997. Search for the competitive edge: a history of dietary fads and supplements. $J$ Nutr 127: S869-S873.

2) Ishihara K, Oyaizu S, Onuki K, Lim K, Fushiki T. 2000. Chronic (-)-hydroxycitrate administration spares carbohydrate utilization and promotes lipid oxidation during exercise in mice. J Nutr 130: 2990-2995.

3) Maughan RJ. 1998. The sports drink as a functional food: formulations for successful performance. Proc Nutr Soc 57: 15-23.

4) Watson JA, Fang M, Lowenstein JM. 1969. Tricarballylate and hydroxycitrate: substrate and inhibitor of ATP: citrate oxaloacetate lyase. Arch Biochem Biophys 135: 209-217.

5) Coyle EF. 1995. Substrate utilization during exercise active people. Am J Clin Nutr 61: 968-979.

6) Graham TE, Spriet LL. 1991. Performance and metabolic responses to high caffeine dose during prolonged exercise. J Appl Physiol 71: 2292-2298.

7) Ivy JL, Costill DL, Fink WJ, Lower RW. 1979. Influence of caffeine and carbohydrate feedings on endurance performance. Med Sci Sports 11: 6-11.

8) Ryu S, Choi SK, Joung SS, Suh H, Cha YS, Lee WK, Lee S, Lim K. 2001. Caffeine as a lipolytic food component increases endurance performance in rats and athletes. $J$ Nutr Sci Vitaminol 47: 139-146.

9) Hellerstein MK, Xie Y. 1993. The indirect pathway of hepatic glycogen synthesis and reduction of food intake by metabolic inhibitors. Life Sci 53: 1833-1845.

10) Lim K, Choi S, Cha YS, Sachan S. 1997. Caffeine complex ingestion increases fat oxidation and endurance performance. FASEB J 11: A490.

11) Powers SK, Byrd RJ, Tulley R, Callender T. 1983. Effects of caffeine ingestion on metabolism and performance during graded exercise. J Appl Physiol 50: 301-307.

12) Lim K, Kim K, Suh H, Lee S, Yoshioka M, Saitoh S, Suzuki M. 1995. The effect of capsaicin on energy substrates utilization at rest and during exercise in rats. Kor J Phys Educ 34: 248-256.

13) Yoshioka M, Matsuo T, Lim K, Suzuki M. 2000. Effects of capsaicin on abdominal fat and serum free fatty acids in exercised-trained rats. Nutr Res 20: 1041-1045.

14) Lim K, Yoshioka M, Kikuzato S, Kiyonaga A, Tanaka H, Shindo M, Suzuki M. 1997. Dietary red pepper ingestion increases carbohydrate oxidation at rest and during exercise in runners. Med Sci Sports Exerc 29: 355-361.

15) Yoshioka M, Lim K, Kikuzato S, Kiyonaga A, Tanaka H, Shindo M, Suzuki M. 1995. Effects of red pepper diet on the energy metabolism in men. J Nutr Sci Vitaminol 41: 647-656.

16) Lee S, Ryu S, Kwon T, Kim H, Park B, Suh H, Lim K. 1998. Effects of carnitine and caffeine complex ingestion on glycogen metabolism in trained rats. FASEB J 12: A4950.

17) Rao RN, Sakariah KK. 1988. Lipid-lowering and antiobesity effect of levo hydrocitric acid. Nutr Res $\mathbf{8}$ : 209-212.

18) Sullivan AC, Tricari J, Neal M. 1973. The influence of (-)-hydroxycitrate on in vivo rates of hepatic gluconeogenesis: lipogenesis and cholesterol-genesis. Fed Proc 33: 556 .

19) Watson JA, Lowenstein JM. 1970. Citrate and the conversion of carbohydrate into fat. $J$ Biol Chem 245: 5993-6002.

20) Lowenstein JM. 1971. Effect of (-)-hydroxycitrate on fatty acid synthesis by rat liver in vivo. J Biol Chem 245: 629-632.

21) Kriketos AD, Thompson HR, Greene H, Hill JO. 1999. (-)-Hydroxycitric acid does not affect energy expenditure and substrate oxidation in adult males in a postabsorptive state. Int J Obes Relat Metab Disord 23: 867873.

22) Van Loon LJ, Van Rooijen JJ, Niesen B, Verhagen H, Saris WH, Wagenmakers AJ. 2000. Effects of acute (-)hydroxycitrate supplementation on substrate metabolism at rest and during exercise in humans. Am J Clin Nutr 72: 1445-1450.

23) Hutber CA, Rasmussen BB, Winder WW. 1997. Endurance training attenuates the decrease in skeletal muscle malonyl-CoA with exercise. J Appl Physiol 83: 1917-1922.

24) Bassett DR Jr, Howley ET. 2000. Limiting factors for maximum oxygen uptake and determinants of endurance performance. Med Sci Sports Exerc 32: 70-84.

25) Noakes TD. 1998. Maximal oxygen uptake: 'classical' versus 'contemporary' viewpoints: a rebuttal. Med Sci Sports Exerc 30: 1381-1398.

26) Runderman NB, Sara AK, Vavvas D, Witters LA. 1999. Malonyl-CoA, fuel sensoring, and insulin resistance. Am J Physiol 276: E1-E18. 